\title{
Digital Identity and Anonymity
}

Desi Manifestations and Regulation

\author{
Rowena Rodrigues \\ School of Law, University of Edinburgh \\ rowena_edw@yahoo.com
}

\begin{abstract}
This paper briefly introduces identity influences, the categorizations of identity and the concepts of anonymity and pseudonymity in India. It also makes a study of digital identity, anonymity and pseudonymity, the manifestations thereof, applications and concerns. It examines the regulation of digital identity vis-à-vis the IT Act 2000, case laws and the implementation of the Multi-purpose National Identity Cards (MNIC's) in India.
\end{abstract}

\section{Introduction}

India is not just a nation with the second largest population in the world and with the world's largest electorate; it is a country constantly in a state of growth and development. It produces supercomputers, launches satellites and has the second largest community of software developers in the world. India has a significant online presence [1] that is constantly growing and expanding and is beginning to face a number of challenges in respect of the digital realm, particularly in relation to identity, anonymity, pseudonymity and their regulation (which are the focal points of study of this paper).

To better comprehend what affects identity in India, we need to take a closer look at its past, present and development. India is a country that has been made and moulded by history of invasions, ruthless colonisation and consequent dramatic divisions. It is a melting pot of different cultures, customs, traditions, rites, rituals and languages. It is a country with a tapestry of assimilation and dissemination, of tolerance, influence and confluences. It is a country steeped in mythology, shrouded by religion and garbed by culture and tradition. On a political note, it is a democratic republic with a strong social welfare agenda.

\section{Identity influences and categories}

There have been many studies on identity in India [2-5]. Cohn [6] states that identity formation in South Asia was influenced by the British colonial census. Jodhka [7] affirms that public discussions and academic discourses on the question of identity in India have been influenced by Hall's views on identity-looking at identity in cultural terms-in terms of one, shared culture, a collective of true self hidden inside the many other more artifically imposed or superficial selves [8].

Please use the following format when citing this chapter:

Rodrigues, R., 2008, in IFIP International Federation for Information Processing, Volume 262; The Future of Identity in the Information Society; Simone Fischer-Hübner, Penny Duquenoy, Albin Zuccato, Leonardo Martucci; (Boston: Springer), pp. 359-374. 
Many writers support the view that while western societies are characteristic of individualism and a certain independence in relations amongst members of society, the case is different in many non-western/eastern societies where relationships (at different levels) play an important and pervasively influential part in all aspects of life [9]. There are strong affiliations, interrelationships and inter-dependencies along with a pervasive spirit of interconnectedness and belonging in such societies. Life and in consequence, the shaping of identities in non-western countries is very much affected and influenced by the bonds of tradition, custom, beliefs [10]. This was the case, and still remains true for modern India.

One key factor that affects identity is religion, perhaps controversially so, as India officially is a secular state with no state religion. Guha stresses how religious identities which are a manifestly accepted part and parcel of life, are not just that but are subject to much "social production and propagation" on a daily basis [11]. Religion is the mainstay of social life with Hinduism having the largest number of followers, followed by Christianity, Jainism, Sikhism, Islam etc.

Hinduism $^{1}$ and its philosophy in particular, has been (and is) a significant identity influence. It is characterised by the existence of a number of gods and goddesses, all governing different aspects of life. Central to it is the Brahmannical triad which represents a union in plurality of form. The triad comprises of Lord Brahma - the God of creation, Lord Shiva- the God of destruction and Lord Vishnu who represents the power of sustenance. This triad represents a plurality of identity and the self as well as at the same time represents a commonality and unification, not unlike the monotheism of the West. There are other gods like Lord Rama, who was immortalized for his 'perfect' nature in the epic Ramayana (not unlike what we often seek to achieve in Second Life [12] or through our avatars in other domains).

Identity and identification in India have also been affected and effectuated by the introduction and promotion of reservation policies [13-16] for the "weaker, disadvantaged" and marginalized sections of society. These policies cover seats in legislature, government jobs and even admissions to universities and colleges and the establishment of identity is primary to the availing of these benefits. Jenkins [17] emphasizes that "contemporary Supreme Court decisions have demonstrated the continuing legal reinforcement of official identity categories."

India is primarily a 'collectivist society' [18]. Many studies have demonstrated how the individual identity is not as important [19] as the group identity [20-22]. Common examples of cohesion are the caste system and the joint family [23]. While life in the cities and towns is more impersonal, life in rural India is characterized by everybody having a deep personal knowledge of the other- villages are small communities with very strong and habitually intimate social bonds.

Courts in India have been called on time and again to decide on matters of identity and identity fraud in relation to social status certificates, conversions, marriage etc. In Kumari Madhuri Patil v Additional Commissioner Tribal Development and others [24], a case of verification of identities, the Supreme Court outlined procedures for

${ }^{1}$ Hinduism basically advocates that there is one supreme god and that God is the supreme self in man. 
verifying identities after stating that identity claims had to be judged on "legal and ethnological basis." In Mrs. Valsamma Paul v. Cochin University \& Ors [25] the Supreme Court further stated that, "people have several identities which constantly intersect and overlap."

Thus, in the light of the above, we can see that identity plays out as a fluid dynamic in Indian society. It can be represented as a whole and a sub-set of the whole. The whole represented by the "indianness" of the self (the overarching national identity), which uniquely comprised a unification of different sub-identities for each individual. The different sub-identities may be sub-classed on the following basis ${ }^{2}$ :

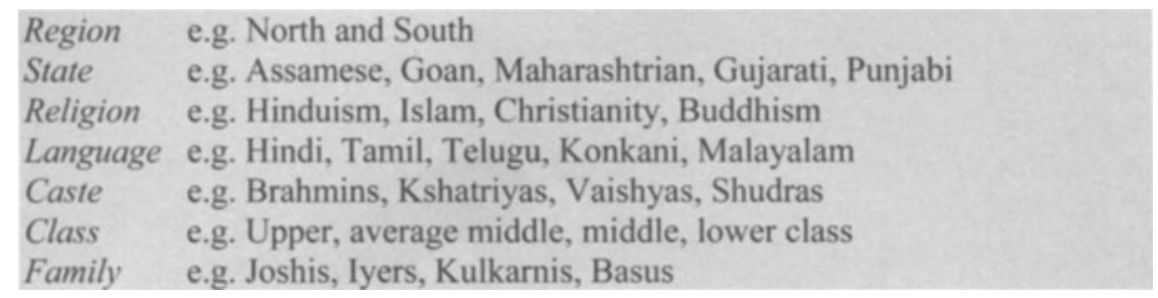

At this stage, one may be compelled to make a comparison between India and the EU. Certainly, there are some strong similarities in identity issues and categorisations. Both India and the EU are made up of distinct states and diverse communities. However, there are some very important reasons why the case of India in identity issues is peculiar and to be considered on its own merits. First, in India although certain legislative powers are devolved to the states and union territories, they are all subject to a single uniformly applied constitution and the sovereignty of the country is democratically and "strongly centrally vested" (unlike the EU which arguably is said to have a weak centre, where only some level of sovereignty has been delegated by nations on specific subjects of interest). Second, as J L de Reede [26] points out, the "centralised judicial testing of primary judicial law" as can be carried out by the Supreme Court in India is virtually non-existent in the $\mathrm{EU}^{3}$. Third, we must also consider the level of development. And finally there are some stark differences in the play of identity issues - for instance, being identified as a member of the Scheduled Castes and Tribes ${ }^{4}$ holds not just social significance but economic and legal repercussions too.

${ }^{2}$ This list is not comprehensive.

${ }^{3}$ Reede states that decentralized reviews do happen in the EU and the testing he talks about is in relation to "the basic constitutional principles in Europe".

${ }^{4}$ For definition see the Constitution of India, Article 366(24) and (25) and Arts. 341 and 342. 


\section{Anonymity and pseudonymity}

In classical Hindu philosophy, one of the four stages of life ${ }^{5}$ was the stage of vanaprastha, or withdrawing from the world and all its ties and becoming a forest dweller. People would completely renounce their material ties, become a sanyasi ${ }^{6}$ and take on a state of non-existence or no identity, where their worldly existence did not matter or simply ceased to be order to attain moksha ${ }^{7}$, which became the ultimate aim of existence.

People have often resorted to changing birth identities and taking on alternate identities. While this may not fit with how we strictly conceptualize anonymity or pseudonymity, it can be likened in some sense to assuming a 'false" identity. For many, birth identities often came to represent a life of segregation, shame and despondency- brought on by stringent social categorizations and distinctions. Many dalits $^{9}$ and untouchables (as they were called) ${ }^{10}$ abandoned their identities by actively adopting alternate ones through religious conversions to escape victimization, isolation and economic and social deprivation [28-30].

There are different degrees of anonymous and pseudonymous behavior evident in practice in India. One such example is the practice of women using veils to cover their head and face (a practice prevalent in many societies in India even today) particularly when they are outside their family home or in a public place.

In the field of art and architecture, artists and sculptors in India in the past did not ascribe their names to their art and the 'resolute anonymity' [31] of the individual Indian artisan, craftsman, printmaker or sculptor' was, and still remains in a number of cases, an accepted fact e.g. the artists that painted Ajanta caves [32].

In literature, the use of pseudonyms was prominent. Authors often adopted pen names as a matter of general practice, e.g. Munshi Premchand (a great Hindi novelist), Bonoful (author, playwright and poet Balāi Chānd Mukhopādhyāy), Firaq Gorakhpuri

5 The four stages of life, applied to males belonging to the twice born Aryan castes, are: Brahmacharya (the instructive stage of life), Grahasta (being a householder), Vanaprastha (withdrawal from life and retreat into the forest) and Mokhsha (liberation from the cycles of rebirth).

6 Sanyasi refers to one with no self-interest or craving for the material world and all in it.

7 Liberation from the cycles of rebirth.

8 Refers to the new identity as opposed to the old pre-determined one.

9 The Dalit Freedom Network defines a dalit as being a "a person who comes from any lower caste, even though technically authentic Dalits are kept outside the caste system as unworthy to enter the social and religious life of society. They are generally considered to be polluted socially, poor economically and powerless politically. They are not allowed to touch caste Hindus and are therefore treated as 'untouchables"' [27].

${ }^{10}$ Untouchability is an offence punishable under law. See specifically, Art. 17, Constitution of India and the Protection of Civil Rights Act, 1955, originally called the Untouchability (Offences) Act 1955. 
(noted contemporary Urdu poet). Perhaps, even interestingly some authors very often appended their pen names to their real names ${ }^{11}$.

The examples above illustrate that in Indian society, individual identities were (and still in many cases are) not the end all. There was also a strong culture and practice of anonymity and pseudonymity, fitting well with the Indian tradition and culture of abdication of the self (into a state of anonymity).

\section{Digital identity and anonymity: Manifestations, Applications and Concerns}

\subsection{Internet Usage}

The Internet has come to represent a key factor influencing change and development in India. Applications of the Internet and digital technology vary from blogging, P2P, digital radio, online games ${ }^{12}$, social networking to video conferencing, distance education, remote diagnosis and troubleshooting etc. The transmission of localized content and services has been made a priority by the government [34]. Take for instance, in Rajasthan, the Neyla village has an information kiosk called "Rajnidhi" which uses ICT to facilitate e-governance [35]. Madhya Pradesh has Gyandoot which connects many villages through Intranet and Soochanalaya kiosks [36]. Other examples are E-Choupal [37] and Tarahaat [38]. Thus digital technology touches not just the lives of the select few in the metropolitan cities and towns but has clearly made inroads into rural areas (nearly $70 \%$ of the Indian population lives in villages) [39].

Cyber cafés are the main mode of access to the Internet in suburbs, towns and metropolitan cities, primarily because home internet access is an expensive prospect since the Internet is still mostly traditionally accessible though dial up connections and broadband has not made the enormous difference it was expected to ${ }^{13}$.

Given access, infrastructure and affordability issues, a single computer is often a multiple access point for Internet access. E Miller's report [42] on the basis of observations recorded in an Indian village evidences another form of digital identity. The report highlights how many residents of an area came to visit the house of an electrician and made use of his computer to send emails, surf the web, download material or simply entertain themselves. The electrician in this case was a kind of a conduit (an Internet service provider of sorts), proficient in English (the main

${ }^{11}$ For instance, Surendra Jha 'Suman', Baidyanath Mishra 'Yatri', Raghupati Sahay 'Firaq' Gorakhpuri

${ }^{12}$ However, gaming is not considered to be a part of mainstream culture and has often been actively discouraged [33].

${ }^{13}$ For a more comprehensive coverage of issues affecting the growth of information technology systems see [40-41]. 
navigatory language of the web). The legal implications of such informal and kind for kind relationships are yet to be established and are cause for further research.

Social networking sites are very popular and Indian users have successfully formed a number of web congregations. Google's Orkut [43] in fact has nearly 6.6 million registered Indian users (of its 49 million worldwide users). A lot of time is devoted to professional networking. Recruitment websites are doing booming business. Usenet groups like soc.culture.indian are widely subscribed to. Indians even resort to the Internet for religious purposes ${ }^{14}$ and even subscribe to personalized astrological services.

Online matrimonial services are very popular ${ }^{15}$. These services often have separate domains for users of different castes, religion and classes e.g. there may be separate domains for Brahmin, Kshatriya, Punjabi, Sindhi or even Vaishya communities. This is evidence of how the strong caste and class influences of the offline world have permeated online and to even greater effect. One specific identity issue related to these matrimonial websites is the creation of profiles thereon. While normally one would register oneself for the use of these services, many times the profiles (containing personal details and photos) registered on these websites are done so by second or third parties (e.g. the mother/uncle of the prospective bride or groom) often with or without the consent of the profiled party. While the top few established companies do (in their effort to self-regulate) make adequate provisions for protection of privacy and identity misuse and theft, there are some that recklessly allow access to personal details of subscribed members without limit, and this is a definite concern that needs to be addressed.

The pre-dominance of the English language on the Internet has been highlighted as a hurdle to expression of lingual sub-identities [44]. Multimedia tools like webcams, microphones and digital telephony have helped overcome this difficulty and have ensured that non-English speaking users can stay connected and use the Internet. Orkut has introduced local language content to cater to its users needs ${ }^{16}$.

Sen $^{17}$ talks about how our freedom in choosing our identities in terms of how others see us is extraordinarily unlimited and Indians have made this discovery and become empowered by the choices they can choose to make in respect of their identities- who they choose to be or not to be - on the Internet ${ }^{18}$. We can chose to be part of a community that is closely linked with what we represent in the offline social context or choose to join a different group altogether. In the real world, identity choices are often constrained by interpersonal recognition.

It is relevant at this point to show how open information and identity sharing is in India and what its influence on digital use is with the help of India's first knowledge village-Hansdehar [45]. The village website [45] purports to be a "web interface for all stakeholders involved in the development and upliftment of the village." The

${ }^{14}$ There are a number of sites offering services, along with forums and communities.

15 e.g. Shaadi.com at http://www.shaadi.com/; Bharat Matrimony http://www. Bharatmatrim ony.com/. Accessed 29 September 2007.

16 Orkut is available in languages like Hindi, Bengali, Marathi, Tamil and Telugu.

${ }_{17}$ Sen, A. 2005. The argumentative Indian.

18 Sen, A. 2005. The argumentative Indian: 351 
village website not only has a citizens' directory, but also has a list of voters and a pensioners list. The Citizens Directory is very comprehensive in its coverage and contains personal data [46] like name, date of birth, age, occupation, sex etc. While this is an alarming proposition from the point of view of data protection and privacy culture and law that is well developed in Europe and other parts of the world, this is nothing to be astounded at in India, for reasons explained earlier as well (openness of knowledge and existence of the sharing principle) as also for the simple reason that the western concept of privacy (and data protection) is yet to trickle down to the grass root level. There is hardly any awareness of the value and marketability of information, as well as its potential for data theft.

A study by Kumaraguru and Cranor [47] contrasted data practices in the US and India. It was found that while a fourth of the US respondents in the study feared identity theft, the issue was by and large ignored by their Indian counterparts. It is evident that some sort of awareness of identity theft and issues concerning protection of personal information and privacy (particularly in the light of the outsourcing data scams) has been increased; there still is a lackadaisical attitude towards identity theft.

\subsection{Digital anonymity}

There is not much evidence to show extensive usage of online anonymous services. This could to some extent be attributed to the lack of awareness of the existence of services like anonymous remailers, anonymous web surfing services etc. Another factor that could explain this would be the time factor - the Internet is very often accessed at cyber cafés which bill users on a minute/hourly basis and users are generally too busy making the most of their limited time either entertaining themselves, corresponding and chatting with loved ones, satisfying their curiosity or applying for jobs to focus on shielding their identity or protecting their privacy through covering their digital trail. Some users simply do not bother because they think they have nothing to hide or are under the mistaken impression that the Internet is a medium that offers them the anonymity that the real world does not.

However, the relative anonymity and pseudonymity of the net (as perceived, though often not achieved) has come to represent empowerment (in terms of breaking traditional social barriers and distinctions impossible in real time), liberation and freedom to a great number of users. The level of conservativeness (as compared to western societies that are much more free and open), is still very high (even given the level of advancement). India is a land with a lot of taboos - e.g. anything related to sex, sexual health and intimacy is taboo. This has created a number of problems in the real world. With the relative anonymity of the Internet, a person with HIV can find the information, advice and help needed (through support groups, like sufferers), without being subject to discrimination and persecution (HIV and AIDS still carry high social stigma) [48-50].

Many people indulge in "anonymous" blogging to deal with social problems and issues (which in real time would attract or result in retribution - political, economic or social). The guise of web anonymity and pseudonymity is thus used to voice genuine grievances, disseminate information and express opinions on a matter of public 
concern as well as post comments [51]. One prominent example is the media criticism blogs - blogs that aim at exposing the corrupt practices in the local media.

Digital anonymity and pseudonymity has of late increasingly come to be associated with the bad and the ugly. Some anonymous bloggers have resorted to using their blogs as platforms to malign and defame. Pseudonymous users have used social networking services to generate ill feeling, hatred and communal discontent [52].

\section{The regulation of identity}

\subsection{The IT Act}

India passed the Information Technology Act $2000^{19}$, the first substantial piece of legislation affecting electronic communications, primarily with a view to facilitate the conduct of ecommerce and e-governance. The Act, a welcome legislative initiative, while commendable in its features has come under severe criticism for not adequately addressing problems generated by the use of the Internet and other computer based services [53-55].

The Act seeks to "provide legal recognition for electronic forms of communication and transactions carried out by means of electronic data interchange and other means of communication, commonly referred to as electronic commerce." The Act also touches upon privacy, ${ }^{20}$ breach of confidentiality, validifies digital signatures, creates information technology offences, sets out authorities to regulate the sector, and made consequential amendments to related existing laws.

One of the most significant criticisms leveled against the Act, and most relevant to the discussion at hand, is the provision that the Act makes for the interception of information transmitted through a computer resource if "necessary or expedient...in the interest of the sovereignty or integrity of India, the security of the State, friendly relations with foreign states or public order or for preventing incitement to the commission of any cognizable offence ${ }^{21}$ ". This provision has been questioned for its potential for misuse by corrupt and oppressive governments as a tool of victimization $^{22}$. This fear is not unfounded given past events and historical developments.

There is no express concept of "personal data" in the Act - data in the Act is defined as being, "a representation of information, knowledge, facts, concepts or instructions which are being prepared or have been prepared in a formalized manner, and is intended to be processed, is being processed or has been processed in a computer system or computer network, and may be in any form (including computer

1921 of 2000 , entered into force on $17^{\text {th }}$ Oct. 2000, vide G.S.R. 788 (E), $17^{\text {th }}$ Oct. 2000.

${ }^{20}$ See Section 76 of the IT Act 2000.

21 See Section 69 of the IT Act 2000.

22 See Duggal, P. 2001. Cyberlaw in India. 
printouts magnetic or optical storage media, punched cards, punched tapes) or stored in the memory of the computer ${ }^{23}$."

Chapters IX and XI of the Act create cyber crimes in relation to unauthorized access to computers, computer systems, computer networks or resources, unauthorized alteration, deletion, addition, modification, alteration, destruction, duplication or transmission of data, computer database, etc

\subsection{Cases}

India's first case of cyber stalking brought digital identity into the spotlight. A man misused a woman's identity in a chat room on the www.mirc.com website ${ }^{24}$ and gave out her personal information like name, telephone number and address to other people resulting in the woman being personally harassed and troubled. The man was prosecuted under S.509 of the Indian Penal Code ${ }^{25}$ after his IP address was traced.

Another similar case was that of the State of Tamil Nadu v Suhas Katti [56]. This case concerned the posting of obscene, defamatory and annoying messages about a divorcee woman in the Yahoo! message group. The perpetrator also forwarded emails to the victim for information through a false e-mail account which he had opened in her name. The woman got annoying phone calls from people who were under the misapprehension that she was soliciting. The accused was arrested and found guilty of offences under Ss. 469, 509 IPC and 67 of Information Technology Act 2000 and was successfully convicted and sentenced for the offence ${ }^{26}$.

In Nasscom v. Ajay Sood \& Others, 27 the Delhi High Court declared phishing to be an illegal act entailing an injunction and the recovery of damages. The Court laid down the ambit of phishing and declared it to be a form of internet fraud where a person pretended to his advantage to be a legitimate association, like a bank or an insurance company in order to extract personal data from a customer such as access codes, passwords, etc. The Court further stated that phishing, was an illegal act and defined to specifically as being "a misrepresentation made in the course of trade leading to confusion as to the source and origin of the e-mail causing immense harm not only to the consumer but even to the person whose name, identity or password is misused."

The identity concerns of social networking sites (SNS) were brought home with a bang when a student was arrested for creating a classmate's profile and uploading her picture along with offensive messages [57].

While all the above cases show that the IT Act and criminal law is successfully being used (albeit limitedly) to prosecute and convict identity fraudsters and criminals, it can safely be concluded that as compared to developments in other parts

23 Sec. 2 (1) (0), IT Act 2000

${ }^{24}$ www.mirc.com

25 Act No. 45 of Year 1860.

${ }^{26} \mathrm{~S}$. 67 of the IT Act 2000 deals with the publishing of information which is obscene in electronic form.

272005 (30) PTC 437 
of the world, India's digital identity problems are still in their nascent stages. One reason for this could be that Indians do not attribute the same level of value to personal information associated with their identities, as perhaps do people in western societies where personal information is of immense economic value (but perhaps India will be heading the same way!). Another reason could be the relatively low usage of ecommerce. There is also the concern that some offences are not being reported $^{28}$ for lack of awareness on the part of digital users (particularly private users) and investigated for lack of awareness in the policing sector.

\subsection{Multipurpose National Identity Cards (MNIC)}

On 26 May 2007, in keeping with current trends of social sorting [58], the Government of India rolled out the Multi-purpose National Identity Cards (MNIC) at Pooth Khurd, Narela [59]. This heralds a step towards a state of definitive and conclusive identification and a dossier society [60] which of late seems to have increasingly become a global regulatory fad.

The MNIC Scheme aims at providing a "credible individual identification system and simultaneous use for multifarious socio-economic benefits and transactions within and outside the Government" for efficient e-governance [61].

The Citizenship Act 1955 was amended in December 2003 [59], to provide for compulsory registration of all citizens and issue of a national identity card. Prior to implementation, a pilot project had earlier been initiated in November 2003 to test the proposal in Assam, Delhi, Goa, Gujarat, Jammu \& Kashmir, Rajasthan, Tripura, Uttar Pradesh, Uttarakhand, Tamil Nadu, West Bengal, Andhra Pradesh, and Pondicherry. Data, in targeted sectors of the pilot areas was collected using the census approach. Particulars of individuals above 18 years of age were ascertained and photographs and finger biometrics were collected.

The MNIC Scheme is to be supported by a Citizens Database, which in turn will be supported by 20 fully technologically equipped centres at the Tehsil/Block headquarters. Bharat Electronics Limited (BEL) has been entrusted with the back end management of these centres. The CPSUs [Consortium of Central Public Sector Undertakings comprising Bharat Electronics Limited (BEL), Electronics Corporations of India Limited (ECIL) and Indian Telephone Industries (ITI)] will handle the personalization of the cards [63].

The MNIC bears a unique 16 digit NIN (National Identification Number) for each citizen. It has a $16 \mathrm{~kb}$ memory microchip. The cards will also contain a finger biometric. The card is secured with asymmetric and symmetric key cryptography, to protect it from falling prey to any tampering or cloning. The process envisaged by the Scheme was to consist of three steps: data collection through field surveys, collection of data and creation of a Citizens Database and verification and validation of the edata against the collected data ${ }^{29}$.

28 A view supported by P Duggal, Supreme Court Advocate. See Gupta, V. No end to cybercrime. Express Computer. 19 November 2007.

29 See Government of India Notice, 9/76/2006 CRD (MNIC). 
The scheme has not been without its critics [64], and even local resistance [65], who argue that the cards give too much control to bureaucrats who may be able to misuse the system to their own ends particularly since there are no express legislative safeguards in place to deal with consequential problems. Sethi [66] goes so far as to state, and not without merit, that India is not ready for the upheaval that the implementation of the MNIC will bring and that this scheme is "part of a proclivity that seeks technological fixes to deal with vast socio-political and economic realities.

It is reported that experts have underlined the key difficulties in implementation of the cards to be the twin problems of illiteracy and lack of documents to support claims of residence [67]. There is a huge section of population in India with what can be termed as negligible 'provable' identity. There is a large migrant population that moves from place to place in search of work, and sets up temporary homes, works for a while and moves on again. In their journeys, they marry, have children and go through life one day at a time. Registration of birth, death and residence is probably the last thing on their mind when they barely eke out an existence [68]. How are such persons who hardly have the means to sustain themselves to prove their identity to meet the MNIC gold standard requirements? Are they lesser citizens of the country than someone who can prove their identity with documents? These concerns have been raised, but there is great concern that policy makers and the executive have failed to take these into consideration before implementing the MNIC scheme.

The MNIC scheme is also fraught with data protection and privacy implications which have not been thought through, or legally catered for by appropriate safeguards. The government's proposal to link various databases to the NIN database ${ }^{30}$ gives us an idea of what is to come and why the privacy conscious are worried.

Briefly, the legal issues that arise from the MNIC scheme can be summarised as follows:

1. Inaccuracies in collection, verification and confirmation of data [69].

2. False identities ${ }^{31}$

3. Data theft/security [70]

4. Data correction issues

5. Function Creep

6. Perpetuation of discrimination

7. Redressal mechanisms

8. Bureaucratic control over personal information without adequate judicial safeguards

Problems in regard to the first point raised above (the collection and verification of data) were evident at the pilot stage itself. In the Murshidabad district of Calcutta, it was reported that there was an alarming probability that $90 \%$ of the population had failed to show proof of nationality (one of the main criteria of the identification exercise) and a large number could not provide supporting documents [71]. In another incident, it was reported that around 400 Bengali and Persian speaking Iranis who came to India and settled here 70 years ago had not been covered.

30 See proposed linkages at http://www.mit.gov.in/plan/ppt/national\%20ID.ppt

31 The electoral history of the country has seen identities (of living and dead persons) being faked and misused for political gain. 
Our experience with the EPICs (Electronic Photo Voter ID Cards) in fact should have taught us a valuable lesson - even till the year 2005 it was reported that only $69 \%$ of the population had defect free cards, and even until lately (nearly 15 years since the cards were implemented, nearly a quarter of eligible voters still do not have one) [72].

What is perhaps the most frightful prospect given India's past history and pluralistic sensitivities is the extent of control that the MNIC database and its linkages will vest in the state and the bureaucracy. What is to stop a renegade government taking drastic measures, or indulging in a bit of ethnic cleansing [73-74] or even forcing all eligible men to undergo vasectomies against their wishes (as was done in the Emergency of 1975-1977) [75]?

\subsection{Other developments}

In late 2006, a news item revealed that the cyber crime cell of the Mumbai police had got Orkut to make an arrangement (albeit informal) called the Priority Reporting Tool, by which Orkut had endeavored not just to block forums and communities containing "defamatory" or "inflammatory" content ${ }^{32}$ but in addition to provide the IP addresses from where such content had been generated [77].

Also last year, the Delhi police (after an increase in terror threats) issued orders to all cyber café proprietors to verify the identities of cyber café users and log details of their entry and exit [78]. There was a wave of criticism for this move, some even seeking to draw the conclusion that India was moving towards a China like regulation of the Net amidst expressions of fear of loss of civil liberties and freedom to browse, or perhaps (as recent reports show) it may just be an Orwellian homecoming [79]! In the same vein, it has been reported that cyber cafés in Mumbai will soon be subject to the CARMS (Cyber Access Remote Monitoring System) which will enable the monitoring of not just email, messaging, web browsing, file transfers but can also be deployed in a wide way to curb access to different sites [80].

\section{Conclusion}

The concepts of digital identity, anonymity and pseudonymity are still taking shape and developing in India. The Internet is a unique portal where individuals freely express, make and have experiences, share personal information and perhaps just be themselves. This paper has demonstrated how cultural, religious and social influences have made their way into the digital play of Indian identity, anonymity and pseudonymity.

With MNIC's, India has moved a level up in making personal information associated with identity more economically and politically valuable. Will this real time "gold standard" for identity find its digital equivalent or perhaps emanate some

32 A PIL was filed against Orkut in this regard [76]. 
influence on digital users in terms of making them realize the value of their personal information? Perhaps this will curb the current traditional value and culture of "openness" explicitly manifest on the web, especially SNSs. Or maybe again it may not. It would all depend on how much economic value came to be attached to identities and identifiers.

But in all this, it is hoped that law will be able to address the underlying and resulting issues and problems effectively. Policy makers (often having other pressing primary concerns), still don't understand technology and the Internet enough to legislate keeping the interests of all stakeholders in mind [81], and the legal and academic community is still finding its feet in this area of law. It remains to be seen whether courts will remain the first port of call for identity issues and whether Indian courts will use international norms and decisions to guide them [82], take into account local peculiarities and enforce local solutions or try and find a middle path.

\section{References}

1. JuxtConsult Online Research \& Advisory, India Online 2007. Report.

2. Paranjpe, A C. 1998. Self and identity in modern psychology in Indian thought. Springer.

3. Gottschalk, P. 2000. Beyond Hindu and Muslim: Multiple identity in narratives from village India. OUP.

4. Chakrabarty, B. 2003. Communal identity in India: Its construction and articulation in the twentieth century. OUP.

5. Singh, Y. 2000. Culture change in India: Identity and globalisation. Jaipur.

6. Cohn, B S. 1971. India: The social anthropology of a civilization. Englewood Cliffs, NJ: Prentice-Hall.

7. Jodhka, S S (ed.). 2001. Community \& identities: Contemporary discourses on culture and politics in India: 26.

8. Hall, S. 1990. Cultural identity and diaspora. In Identity: Community, culture, difference, ed. J Rutherford, 223.

9. Hofstede, G. 1980. Culture's consequences. Sage Publications.

10. Cohn, B S.1987. The census, social structure and objectification in South Asia. In An anthropologist among historians and other essays, 224-254. New Delhi: Oxford University Press.

11. Guha, S. 2003. The politics of identity and enumeration in India c. 1600-1990. Society for Comparative Study of Society and History, 148-167:50.

12. Second Life. Second Life is a $3 \mathrm{D}$ digital world that is the product of its residents' imagination, activity and maintenance. See http://secondlife.com/

13. Pai Panandiker, V A (ed.). 1997. The politics of backwardness: Reservation policy in India. New Delhi. Konark Publishers;

14. Wadwha, K K. 1975. Minority safeguards in India: Constitutional provisions and their implementation. New Delhi. Thomson Press (India) Limited;

15. Galanter, M. 1984. Competing equalities: Law and the backward classes in India. Delhi: Oxford University Press;

16. Nabhi's brochure on reservation and concession. 2001. New Delhi: Nabhi Publications; Reports of the Commissioner for Scheduled Castes and Scheduled Tribes.

17. Jenkins, L. D. 2003. Identity and identification in India: Defining the disadvantaged: 24 . 
18. Geert, H. 1991.Culture and organizations, software of the mind, intercultural cooperation and its importance for survival. McGraw-Hill.

19. Bharati, A. 1985. The self in Hindu thought and action. In Culture and the self: Asian and Western perspectives, ed. A. J. Marsella, 211.

20. Dumont, L. 1970. Homo Hierarchicus: The caste system and its implications. University of Chicago Press: 8-9;

21. Kakar, S. 1981. The Inner world: A psycho-analytic study of childhood and society in India, Delhi, 37;

22. Ramanujam, B.K., Toward maturity: Problems of identity seen in the Indian clinical setting. In Identity and adulthood, ed. S Kakar, OUP, 37-55: 54.

23. Encyclopedia Britannica Online. The joint family, 29 May 2007 http://www.britannica. com/eb/article?tocId=26070.

24. Kumari Madhuri Patil v. Addl.Commnr. Tribal Development (1994) 6 SCC 241.

25. Mrs. Valsamma Paul v. Cochin University \& Ors. JT 1996 (1) SC 57

26. Reede, J L. de. 2006. Protection of basic constitutional features in India and Europe. Book review. European Constitutional Law Review. 2: 476-482.

27. http://www.dalitnetwork.org/go?/dfn/about/C20/\#sc_st_or_scheduled_caste_scheduled_tri bes

28. Stern, R.W. 1993. Changing India: Bourgeois revolution on the subcontinent: 78; BBC News. Dalits in conversion ceremony. 14 Oct. 2006, http://news.bbc.co.uk/1/hi/world/ south_asia/6050408.stm.

29. Gupta, D. Killing caste by conversion. The Hindu, 13 Nov. 2001 http://www.hinduonnet. com/thehindu/2001/11/13/stories/05132523.htm.

30. Chandra, R \& S. Mittra. 2003. Dalit identity in the new millennium. New Delhi, Commonwealth.

31. Rajadhyaksha, A. Presentation at the School of Oriental and African Studies (SOAS). University of London. 24 May 2007

32. Government of India, Visual Arts, paintings and sculptures, http://india.gov.in/ knowindia/visual_arts.php. 27 Sep. 2007; Gupte, R \& B. D. Mahajan. 1962. Ajanta, Ellora and Aurangabad caves. Bombay: Taraporevala \& Co.

33. Badam, R.T. India tech institute curbs internet use. International Business Times. 21 March 2007. http://www.ibtimes.com/articles/20070321/india-internet.htm

34. See GoI. Ministry of Communications and Information Technology, Department of Information Technology, Information technology annual report 2006-07, Accessed 20 Nov. 2007. http://www.mit.gov.in/download/annualreport2006-07.pdf

35. The Society for Promotion of e-Governance, major e-governance projects, 23 Sep. 2007. http://www.egovindia.org/egovportals.html

36. www.gyandoot.nic.in

37. ITC. E-Choupal: ITC's rural development philosophy at work, http://www.itcportal.com/ ruraldevp_philosophy/echoupal.htm. Accessed 1 Sep. 2007.

38. Tarahaat. http://www.tarahaat.com/. Accessed 30 Sep. 2007.

39. Census of India 2001

40. Background Report of the Working Group on Information Technology for Masses, http://itformasses.nic.in/pagel.htm\#bg5a.

41. Fischer \& Lorenz. 2000. Internet and the future policy framework for telecommunications. A report for the European Commission. 31 January 2000: 61 http://europa.eu.int/ISPO/infosoc/telecompolicy/en/Fischer31a.pdf

42. Miller, E. Wireless internet access in rural south India: A report by Eric Miller" December 2000. http://ccat.sas.upenn.edu/ emiller/report.html 
43. Orkut. http://www.orkut.com/. Accessed 29 September 2007.

44. Keniston, K. Panel on global culture, local culture, and vernacular computing: the excluded 95\% in South Asia. http://web.mit.edu/ kken/Public/PDF/Panel\%20on\%20 Global\%20Culture.pdf

45. Smart Villages. http://www.smartvillages.org/hansdehar/people.htm. Accessed 29 Sep. 2007.

46. Art 2(a), Directive 95/46/EC of the European Parliament and of the Council of 24 October 1995 on the protection of individuals with regard to the processing of personal data and on the free movement of such data, OJ L 281, 23.11.1995: 31-50

47. Kumaraguru, P. and L. Cranor. 2005. Privacy perceptions in India and the United States: An interview study. http://www.cs.cmu.edu/ ponguru/tprc_2005_pk_lc_en.pdf. Accessed 15 Sep. 2007.

48. World Bank. HIV/AIDS in India. Aug 2007. http://siteresources.worldbank.org /INTSAREGTOPHIVAIDS/Resources/HIV-AIDS-brief-Aug07-IN.pdf.

49. BBC News. Bareth, N. Court puts on hold HIV decision. BBC News. 28 Sep. 2007. http://news.bbc. co.uk/1/hi/world/south_asia/7017573.stm.

50. BBC News. 'HIV stigma' drives India suicide. 3 Jul 2006. http://news.bbc.co.uk/1/hi/ world/south asia/5141100.stm

51. Glaser, M. Indian media blog shuts down after legal threats from Times of India. Online Journalism Review. Annenberg School of Journalism. University of Southern California. 15 March 2005. http://www.ojr.org/ojr/stories/050315glaser

52. PTI. Pune cops book Orkut user. The Times of India. 2 September 2007. http://timesofindia.indiatimes.com/Pune_cops_book_Orkut_user/articleshow/2331802.cms

53. Sreekala, G. Much hyped IT Act stays a dead letter. Times News Network. 20 July 2006. http://economictimes.indiatimes.com/News/Business_Law/General_Law/Much_hyped_IT Act_stays_a_dead_letter/articleshow/1783026.cms.

54. Duggal, P. Cyberlaw in India: The Information Technology Act 2000 - Some perspectives. 6 Sep. 2001 . http://www.mondaq.com/article.asp?articleid=13430\&print=1.

55. Basu, S. \& R Jones. March 2003. E-commerce and the law: A review of India's Information Technology Act 2000.Contemporary South Asia. 12(1): 7-24.

56. Singh, T. Cyber law and information technology. http://www.delhidistrictcourts. nic.in/CYBER\%20LAW.pdf. Accessed 3 Sep. 2007

57. Nikade, N. Youth misuses classmate's profile, posts lewd scraps. Mumbai Mirror. 29 September 2006.

58. Lyon, D. November 2004. Identity cards: social sorting by database. Oxford Internet Institute. Internet issue brief No 3: 3

59. Ministry of Home Affairs. First tranche of multi-purpose national identity cards handed over to the citizens. Press Information Bureau. 26 May 2007. http://pib.nic.in/ release/release. asp?relid $=28238$

60. Mehmood, T. From chowkeydari act to biometric identification: Passages from the information state in India. International colloquium on information society. History and politics. Sarai CSDS. New Delhi. 29 Nov-2nd December 2006. http://www.sarai.net/ research/information-society/resources/texts-and-essays/from_chowkeydari_act.pdf

61. Office of the Registrar General India. 2003. Project review: Multi-purpose National Identity Card. E-censusIndia, Issue $17 \mathrm{http} / / / \mathrm{www} . c e n s u s i n d i a . n e t / r e s u l t s / e c i 17 . p d f$

62. Citizenship (Registration of Citizens and Issue of National Identity Cards) Rules, 2003 were notified in the Government of India Gazette Vide GSR No. 937(E) dated 10 December 2003. 
63. Ministry of Home Affairs. First tranche of multi-purpose national identity cards handed over to the citizens. Press Information Bureau. 26 May 2007. http://pib.nic.in/ release/release.asp?relid=28238Ministry of Home Affairs, Press Release

64. SAHRD. Multi-purpose national identity: Protection or restriction of right. HRF/169/07. 13 July 2007. http://www.hrdc.net/sahrdc/hrfeatures/HRF169.htm

65. Vishwa Mohan. Multi-purpose smart cards arrive," Times News Network. 24 May 2007. http://timesofindia.indiatimes.com/Cities/Delhi/Multi-purpose_smart_cards_arrive/article show/2070343.cms; No need for a new ID care scheme: CPI-M tells poll panel.4 April 1998. The Statesman.

66. Sethi, A. December 2005. Peeking out of your pocket: India's national ID scheme is 'on schedule.' http://www.himalmag.com/2005/november/analysis_7.html

67. Merinews Network. I-cards for Indian citizens as govt. launches MNIC project. Merinews. 28 May 2007. http://www.merinews.com/catFull.jsp?articleID $=125184$

68. Prabhu, R. 2003. From national ID to global citizenry. Convergence Plus. http://www.convergenceplus.com/3rd\%20scti\%202003.html

69. Mehmood, T. 2005. Playing cards- identity cards and the politics of information. World Information City, Bangalore. 14- 19 Nov. 2005 http://www.sarai.net/research/ informationsociety/resources/texts-and-essays/playing_cards.pdf

70. Srinivasan, S. Now, for the born identity. The Economic Times. 1 Sep. 2007.

71. Purohit, D. Report taking shape amid infiltration buzz. The Telegraph Calcutta. 23 Aug. 2005. http://www.telegraphindia.com/1050823/asp/nation/story_5136259.asp

72. Misra, N. 186 million Indians without voter IDs. Hindustan Times, 15 May 2007. http://www.hindustantimes.com/storypage/storypage.aspx?id=df526e99-d0d6-4235-b3d6 9f964ae0b445\&\&Headline $=186+$ million + Indians + without + voter+IDs

73. Fussell, J. 2001. Group classification on national ID cards as a factor in genocide and ethnic cleansing. Presented on 15 Nov. 2001 to the Seminar Series of the Yale University Genocide Studies Program.

74. Longman, T. 2001. Identity cards, ethnic self-perception, and genocide in Rwanda. In Documenting individual identity: The development of state practices in the modern world. ed. J Caplan and J Torpey. Princeton University Press.

75. Tarlo, E. 2003. Unsettling memories: Narratives of the 'emergency' in Delhi. C Hurst \& Co.

76. TNN. PIL seeks ban on Orkut. Times of India. 24 Nov 2006. http://timesofindia. indiatimes.com/Cities/Mumbai/PIL_seeks_ban_on_Orkut_/articleshow $/ 548286 . c m s$

77. Times News Network. Orkut's tell-all pact with cops. The Economic Times Online. 1 May 2007

78. IBN Live. Photo ID must for cyber cafe users. IBN Live. 21 July 2006. http://www.ibnlive.com/news/photo-identity-cards-for-net-users/16297-3.html

79. Varma, A. India's cops get Orwellian. LiveMint.com. 6 September 2007. http://www.livemint.com/2007/09/06000800/India8217s-cops-get-Orwelli.html

80. Menon, V. K. Virtual khabris to zoom-in on terrorists. Midday. 29 August 2007. http://www.mid-day.com/news/city/2007/august/163165.htm

81. Wolcott, P. 2003. Global diffusion of the internet I: India: Is the elephant learning to dance? Communications of the Association for Information Systems. Volume 11, 560646: 627

82. Jolly George Varghese v. Bank of Cochin, [1980] 2 SCJ 358 